\title{
Temor y temblor: \\ antes y después del terror cinematográfico en el \\ videojuego
}

\author{
Diego Maté
}

Recibido: 30.10.2020 — Aceptado: 01.12.2020

\section{Titre / Title/ Titolo}

Peur et tremblements: avant et après l'horreur cinématographique dans le jeu vidéo

Fear and Shiver: before and after Film Horror in Videogames

Paura e tremore: prima e dopo l'orrore cinematografico nel videogioco

\section{Resumen / Résumé / Abstract / Riassunto}

El videojuego mantiene todo tipo de intercambios con el cine. El terror es un campo especialmente interesante para atender a los diálogos, los vaivenes y los silencios entre los dos medios. En los años 80, el videojuego trabaja con iconografías y motivos del terror cinematográfico. Se notan intentos precarios de imitar formas del sobresalto propias del género en cine pero sin llegar a apropiarse de recursos del lenguaje del cine y sin establecer un género videolúdico. El crecimiento de los motores gráficos en 3D de los 90 permite replicar recursos del lenguaje cinematográfico. La operación que condensa esta transformación es el jumpscare, elemento que modeló la enunciación del género. El survival horror se afianza como la primera forma estable de terror videolúdico. Después de 2010, el videojuego entra en un nuevo período y ensaya estrategias de shock por fuera de su relación con el cine. Algunos juegos abandonan el realismo tridimensional y los recursos cinematográficos para volver sobre desarrollos estilísticos previos y explorar el registro incierto y la vacilación de lo fantástico. Cada etapa reúne estrategias textuales que movilizan, en el plano de la enunciación, distintas formas de conmoción. El terror cinematográfico funciona como condición de producción de los dos primeros momentos, mientras que el tercero reenvía hacia el propio pasado mediático del videojuego y procura allí los insumos expresivos para desplegar nuevas formas de sobresalto.
Le jeu vidéo a toutes sortes d'échanges avec le cinéma. La terreur est un domaine particulièrement intéressant pour assister aux dialogues, aux hauts et aux bas et aux silences entre les deux médias. Dans les années 80 , le jeu vidéo fonctionne avec des iconographies et des motifs de terreur cinématographique. On note des tentatives précaires d'imiter des formes de choc typiques du genre au cinéma, mais sans s'approprier les ressources du langage cinématographique et sans établir un genre vidéoludic. La croissance des moteurs graphiques 3D des années 90 permet de reproduire les ressources du langage cinématographique. L'opération qui condense cette transformation est le jumpscare, un élément qui a modelé l'énonciation du genre. Le survival horror est établie comme la première forme stable de jeu vidéo d'horreur. Après 2010, le jeu vidéo entre dans une nouvelle période et répète des stratégies de choc en dehors de son rapport au cinéma. Certains jeux abandonnent le réalisme tridimensionnel et les ressources cinématographiques pour revenir à des développements stylistiques antérieurs et explorer le registre incertain et l'hésitation du fantastique. Chaque étape rassemble des stratégies textuelles qui mobilisent, au niveau de l'énonciation, différentes formes de choc. La terreur cinématographique fonctionne comme une condition de production des deux premiers moments, tandis que le troisième renvoie au passé trèsmédiatique du jeuvidéo et y cherche les apports expressifs pour déployer de nouvelles formes de choc.

Videogame maintains all kinds of exchanges with cinema. Terror is a particularly interesting field in attending to the dialogues, the ups and downs and the silences between the two media. In the 80s, videogames works with iconographies and motifs of cinematic terror. Precarious attempts to imitate forms of shock typical of the genre in cinema are noticeable, without an appropriation of the resources of cinema language or the establishment of a proper genre. The growth of $3 \mathrm{D}$ graphic engines in the 
90s allows to replicate resources of film language. The operation condensing such transformation is the jumpscare, the element that modeled the enunciation of the genre. Survival horror is consolidated as the first stable form of videoludic terror After 2010, videogame enters a new phase and practices shock strategies outside its relationship with cinema. Some games abandon three-dimensional realism and cinematographic resources to return to previous stylistic developments and explore the uncertain register and vacillation of the fantastic. Each stage brings together textual strategies that mobilize, on the level of enunciation, different forms of shock. Cinematographic terror functions as a production mode for the first two phases, while the third one refers back to the mediatic past of videogame, seeking there the expressive supplies for the deployment of new forms of shock.

Il videogioco mantiene varie tipologie di intercambio con il cinema. Il terrore è un campo particolarmente interessante per analizzare i dialoghi, gli andirivieni e i silenzi tra i due media. Negli anni ' 80 , il videogioco utilizza iconografie e motivi del terrore cinematografico. Notiamo tentativi precari di imitazione delle forme di shock tipiche del genere cinematografico, ma senza una appropiazione delle risorse del linguaggio cinematografico e senza la definizione di un genere videoludico. Lo sviluppo dei motori grafici 3D degli anni ' 90 permette di replicare le risorse del linguaggio cinematografico. L'operazione che condensa questa trasformazione è il jumpscare, elemento che ha modellato l'enunciazione del genere. Il survival horror si afferma come la prima forma stabile di orrore da videogioco. Dopo il 2010, il videogioco entra in una nuova fase e prova strategie d'urto al di fuori del suo rapporto con il cinema. Alcuni giochi abbandonano il realismo tridimensionale e le risorse cinematografiche per tornare agli sviluppi stilistici precedenti ed esplorare il registro incerto e le vacillazioni del fantastico. Ogni tappa riunisce strategie testuali che mobilitano, a livello di enunciazione, diverse forme di shock. Il terrore cinematografico funziona come modo di produzione per i primi due momenti, mentre il terzo rimanda al passato mediatico del videogioco e cerca lì le modalità espressive per dispiegare nuove forme di soprassalto.

\section{Palabras clave I Mots-clé $I$ Key words /Parole chiave}

Videojuego, cine, terror, enunciación, survival horror.

Jeu vidéo, cinéma, terreur, énonciation, Survival horror.

Videogame, cinema, horror, enunciation, survival horror.

Videogioco, cinema, terrore, enunciazione, survival horror.
De los intercambios del videojuego con otros medios y lenguajes, los realizados con el cine son especialmente numerosos y diversos. Si hubiera que hacer un resumen muy somero, habría que referirse a por lo menos cuatro modalidades dominantes: la transposición, en la que el medio se apropia de materiales emplazados inicialmente en el cine ${ }^{1}$; la cinemática, en la que el videojuego suspende la interacción y replica el lenguaje del cine; la representación tridimensional y fotorrealista, que trabaja un punto de vista semejante al de una cámara; juegos recientes, como Her Story (2015) o Telling Lies (2019), en los que hay que manipular fragmentos de registro audiovisual.

Algunas transformaciones especialmente interesantes se produjeron en el campo del videojuego y el terror. En este trabajo, desde una perspectiva sociosemiótica (Verón, 1998; Steimberg, 2013), nos ocuparemos de dar cuenta de las distintas formas de relación que el videojuego mantuvo con el terror fílmico y cómo fue que el primero elaboró distintas estrategias mediáticas para replicar elementos del lenguaje cinematográfico. Cada una de estas estrategias supone una gramática discursiva con un repertorio de operaciones estable que organiza una zona determinada de la producción del videojuego. A su vez, cada una resume distintos modos de apropiación mediante los cuales el videojuego leyó el terror cinematográfico. Nos concentraremos, entonces, en tres etapas: la primera, en la que el videojuego toma apenas algunos pocos rasgos iconográficos y semánticos del terror fílmico; una segunda, en la que se asienta el género survival horror y se replican recursos del lenguaje cinematográfico; y una tercera, en la que emerge un nuevo terror videolúdico que ya no tiene como modelo el cine sino la propia producción mediática de momentos tecnológicos previos.

Ese recorrido estará signado, a su vez, por la operación del jumpscare y su funcionamiento enunciativo, es decir, por la forma en la que los casos, a través de ese recurso,

1 Con «cine» me refiero a la producción cinematográfica de mayor proyección social. Metz (1974) ya había advertido que la clasificación «cine» remite socialmente a una zona específica de la oferta mediática, esto es a los géneros narrativos y, tal vez, a una pequeña área del documental. 
despliegan una propuesta de contacto, una escena comunicativa. En este sentido, la pregunta que nos formulamos es plenamente discursiva y no psíquica o emotiva, apunta a textos entendidos en su materialidad y no al trabajo de la cognición. La aclaración se debe a que en los estudios sobre el terror, cinematográfico o de otros lenguajes, suele predominar el abordaje cognitivo o centrado en las emociones del receptor; Filosofía del terror o paradojas del corazón, de Noël Carroll, es un ejemplo paradigmático de estos enfoques, de los que tomamos distancia.

Respecto del corpus elegido, el criterio para la selección de los ejemplos varía ligeramente en cada uno de los momentos analizados. En el primero se tomaron tres juegos que condensan las estrategias de un medio todavía en sus inicios a la hora de tematizar el terror. En el segundo, dedicado al survival horror, se trabaja con los tres juegos que establecieron el género en los 90. En el tercero, ya no se trata de sintetizar una zona regular de la producción, sino de mostrar una serie de quiebres, por eso los tres casos presentan muchas diferencias entre sí y comparten el hecho de tematizar el terror y el de remitir a estilos videolúdicos del pasado. Dar cuenta, aunque sea de manera muy resumida, de las aperturas que efectúa este tercer y último período requería de un corpus menos rígido y un poco más volátil.

En relación con la procedencia del corpus, la mayoría pertenece a estudios o desarrolladores estadounidenses. Son varios los motivos que explican la elección: uno, que la producción estadounidense es la que posee mayor proyección en el mercado Occidental; dos, que la escena del videojuego de terror (pero también de otros géneros) tiene rasgos distintos en Oriente, sobre todo en Japón, por lo que eso implicaría seguramente un estudio muy diferente. Finalmente, respecto de los juegos de origen japonés trabajados (Resident Evil y Silent Hill), hay que decir que tuvieron una amplísima circulación en Occidente y que rápidamente contribuyeron a establecer allí el género de survival horror. Por eso es que, más allá de su procedencia, se los incluye en una «serie» occidental; en contraposición, atender a las formas en las que esos juegos incidieron en la producción asiática supondría un panorama seguramente muy distinto.

\section{Terror cinematográfico}

Como es sabido, se habla de películas de terror desde los comienzos de la historia del cine (Prince, 2004). Las definiciones del género y sus variantes son numerosas, lo mismo que sus periodizaciones. A los fines de trazar los contornos elementales del cine de terror al que refieren los primeros juegos survival horror, resulta útil la periodización de Isabel Pinedo (2004). La autora divide la historia del género en dos grandes momentos bien diferenciados que denomina clásico y posmoderno. Como suele suceder en este tipo de periodizaciones, el segundo momento se construye en franca oposición con el primero. Según Pinedo, el terror clásico se caracterizó por trabajar alrededor de la representación de un monstruo (o de un conjunto de ellos), ubicando la fuente del mal en algún sitio lejano, separado de los espacios cotidianos. El relato es claro y escenifica un conflicto nítido entre las fuerzas de la razón y de lo sobrenatural; la exposición narrativa privilegia esa colisión hasta que las primeras se imponen neutralizando o expulsando lo sobrenatural con la ayuda de instituciones como la ciencia o, a veces, la religión. Finalmente, la incertidumbre y la conmoción producidas por el conflicto ceden ante la restauración del orden. Este período coincide con la Era Dorada de Hollywood: las películas del estudio Universal y su perenne repertorio de criaturas son algunos de sus signos más distintivos.

Lo que Pinedo llama terror posmoderno empieza alrededor de las décadas de 1970 y 1980 y marca un quiebre en varios niveles. La amenaza ya no se origina en lugares lejanos o exóticos sino que emerge de espacios conocidos y familiares. Los oficios del ser humano ya no alcanzan a contener el mal y ese fracaso habilita el asedio de la vida cotidiana. El abanico semántico se expande permitiendo el despliegue de nuevos temas, por ejemplo, el del temor a un semejante que pudiera estar contaminado o poseído por un invasor externo. La tensión entre lo científico y lo sobrenatural se atenúa, así lo evidencian, según la autora, figuras como la de Jason, de la saga Viernes 13, Michael Myers, de Halloween, y otros slashers de moda que encarnan una maldad ciega, 
sin razones ni propósitos, a la que solo queda combatir en sus propios términos violentos. El conflicto abierto ya no vuelve a cerrarse, la amenaza nunca se disipa del todo; al final se restaura un nuevo equilibrio narrativo en el que ya no es posible el gobierno la razón.

Esta periodización admite sin dudas reparos y matices, pero resulta de utilidad para delimitar de manera global los rasgos de la producción a la que remiten los juegos de los dos primeros momentos analizados.

\section{Flashback}

Durante las dos primeras décadas de vida del videojuego, hubo juegos que se apropiaron de uno u otro elemento asociado al terror cinematográfico y sus variantes, pero esa apropiación siempre fue parcial, localizada y no incluía la propuesta enunciativa, el contrato de lectura (Verón). Estos juegos imitaban algunas operaciones de superficie del terror fílmico pero no desplegaban la misma escena comunicativa. En la década del 80 se asienta el primer sistema de géneros del medio con la estabilización de géneros como el juego de plataformas, de lucha, de puzzle, el shooter o la aventura gráfica (Kent, 2001), pero hasta la década siguiente no habrá nada parecido a un terror videolúdico.

Uno de los primeros juegos en remitir al universo del terror es Haunted House (1981). El espacio es una casa de

Haunted House

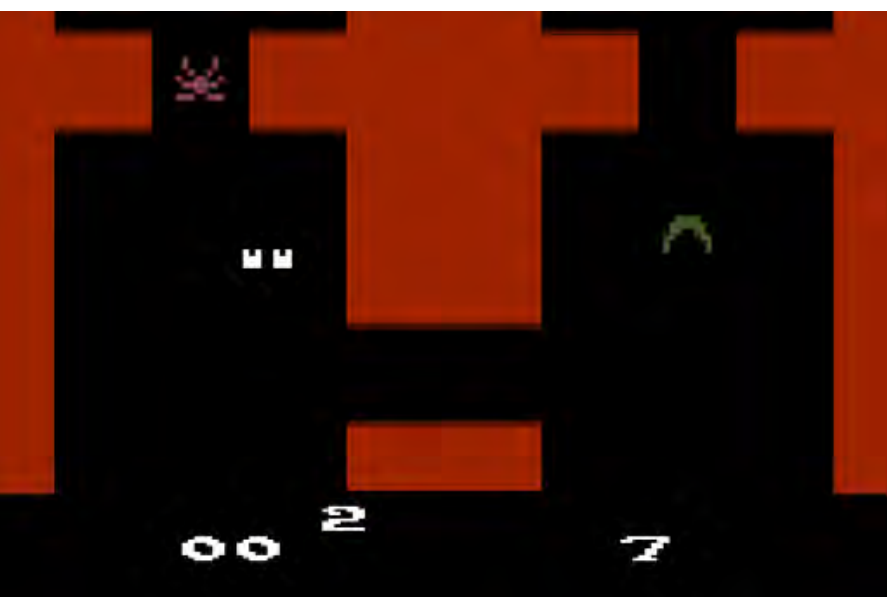

cuatro pisos dividida en habitaciones por las que hay que desplazarse en busca de cálices (condición para la victoria), fósforos (que permiten ver en la oscuridad) y bastones mágicos (que ahuyentan fantasmas). Haunted House replica una iconografía y un setting asociados al terror que incluye algunos de sus motivos de mayor proyección cultural como la casa embrujada, monstruos, alimañas o la alternancia entre luz y oscuridad (Pinedo, 2004). Lo más parecido a una operación enunciativa lo constituye el ataque subrepticio de la criatura. Esto delimita una propuesta de contacto signada por la tensión y la amenaza constante, el texto no ofrece instantes de reposo o seguridad, cada momento del trayecto alberga el peligro de un ataque y la posibilidad de una huida improvisada.

Por supuesto, se trata de una tensión muy diferente a la trabajada por el género de terror en el cine. Sin embargo, a pesar de esas diferencias, que competen a la dimensión de las materias de la expresión, de la sensorialidad (Metz, 1974), el juego consigue replicar, aunque sea de manera tenue, la inquietud que el género construye en el cine.

A Haunted House le siguen algunos otros juegos que trabajan a partir de ese mismo efecto. En Halloween (1983), transposición de la película de John Carpenter, hay que moverse a través de un espacio dividido horizontalmente en busca de un arma para enfrentar a Michael Myers. Mientras tanto, se debe ayudar a escapar a niños acechados por el asesino. El ataque sorpresivo proviene ahora de los límites laterales de la pantalla o

Halloween

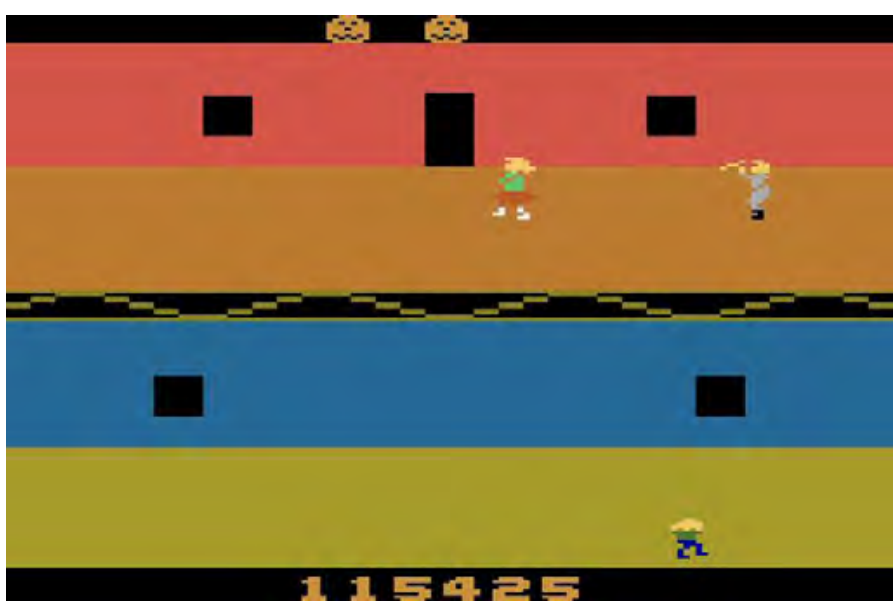


de algunas de las puertas: cada vez que Myers aparece, siempre de manera imprevista, el leitmotiv musical de la película irrumpe y signa el clima de peligro.

En Friday the 13th (1985), otra transposición de una franquicia de terror fílmico, la premisa es ligeramente distinta: en el campamento de Lake Cristal, compuesto por un espacio de grandes proporciones, se encuentra Jason disfrazado. El juego consiste en descubrir al asesino antes que este aniquile al grupo. En la versión para Commodore 64, una vez que se llega a ciertos lugares del camping, el juego es interrumpido por el sonido de un grito y una imagen fija, por ejemplo, con calaveras o con los restos destrozados de uno de los campistas. Estos momentos buscan replicar el jumpscare del cine de terror disponiendo un shock audiovisual que interrumpe el flujo lúdico.

El jumpscare, en tanto recurso que parece haber signado la vida del terror fílmico y de sus subespecies (Bishop), no ha sido objeto de muchos estudios ${ }^{2}$. El término pertenece a la cultura popular y designa una operación mediante la cual se busca sobresaltar al espectador, muchas veces mediante la aparición de un monstruo o de un ataque sorpresivo (Draven, 2013; Muir, 2013). En un filme, esta operación suele consistir en la irrupción imprevista y agresiva de algún elemento en el campo visual o sonoro. Hanich propone una tipología de seis formas en las que el cine de terror puede sobresaltar al espectador: nos centraremos en el tipo que Hanich denomina horror shock ${ }^{3}$ y que consisten en la «revelación abrupta de un monstruo o de un acto de violencia» (131). A su vez, el autor describe tres vías

2 Hanich (2010) se pregunta por la curiosa escasez de estudios respecto de un procedimiento tan ubicuo y encuentra que no solo los investigadores y los críticos ignoran o denostan el jumpscare, sino que hasta incluso directores de terror que lo emplean con frecuencia reniegan del recurso.

Un breve comentario respecto de los términos shock y jumpscare, que empleo de la siguiente manera: el jumpscare refiere a una operación retórica (la aparición de un monstruo o de un peligro insospechado, la irrupción de la banda sonora, un cambio visual brusco, etc.), mientras que el shock da cuenta de un rasgo enunciativo, un elemento que modela las figuras del dador del texto, del destinatario del texto y la relación entre los dos. La noción de shock sintetiza la gestión de una escena comunicativa que persigue, siempre en términos discursivos y no empíricos (no hablamos de sujetos sino de posiciones textuales), el sobresalto, la intempestividad, la conmoción. Por supuesto, este es el uso que yo hago de los términos para diferenciar dos niveles de análisis (retórico y enunciativo), y puede que los autores mencionados los utilicen con otras acepciones, o que no distingan entre uno y otro término.

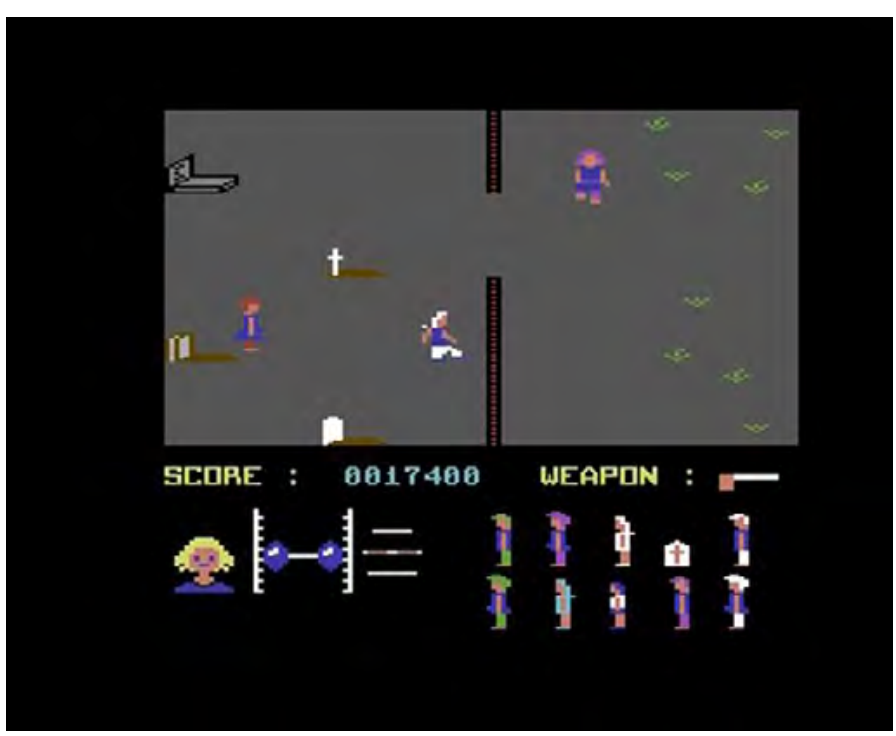

Friday the 13th

mediante las cuales puede elaborarse el efecto: corte abrupto, ingreso al plano desde el espacio off y movimiento dentro del plano. Casi todos los casos analizados construyen el jumpscare a través de la segunda vía: mediante del ingreso imprevisto de un monstruo en el campo visual ${ }^{4}$.

Si bien se lo suele asociar con el terror contemporáneo, el jumpscare puede rastrearse al menos hasta la producción cinematográfica de la década de 1920 (Rivie1lo). En el presente, el término puede referirse además a distintas formas de generación de sobresaltos en el videojuego o en textualidades breves de internet (como videos cortos o gifs) que tienen como condición de producción el efecto cinematográfico.

Los casos mencionados sugieren una tendencia temprana: el videojuego, sin poder todavía imitar operaciones de la audiovisualidad cinematográfica, se apropia del terror de manera predominantemente iconográfica y temática, pero no enunciativa. Los juegos trasladan historias prototípicas y motivos como los de la casa maldita o relatos del cine reciente, a un formato

\footnotetext{
La única excepción la ofrece Friday the 13th: la irrupción de alguna de las imágenes mencionadas, que ocupan toda la pantalla, ya no hace entrar en el campo visual un elemento inesperado sino que procede por algo parecido al jump cut, es decir, como si fuera un corte, una operación de montaje.
} 
que privilegia el despliegue del espacio y sus trayectorias por sobre cualquier rasgo narrativo o mimético, explotando las posibilidades expresivas de ese momento mediático del videojuego. Este estado de cosas se mantiene más o menos estable hasta comienzos de la década del 90.

\section{Un nuevo género}

En otro espacio propuse una periodización del videojuego atendiendo a dimensiones semióticas relativas al dispositivo, los géneros y los estilos y las remisiones al pasado mediático (Maté, 2020). Esta periodización tiene cuatro momentos. El primero comprende la producción inicial, que llega hasta finales de la década del 70, todavía algo caótica y dispersa, en la que el videojuego transpone formas lúdicas preexistentes mientras desarrolla otras nuevas que no terminan de estabilizarse. El segundo momento abarca la década del 80, cuando los moldes de la previsibilidad social pasan a organizar la producción del medio y se establece un primer sistema de géneros (que no incluye el terror, como acabamos de observar en el apartado anterior). El tercer momento empieza en los 90, cuando la expansión de los motores gráficos en tres dimensiones señalan una ruptura respecto de la producción previa: con el lanzamiento de juegos como Wolfenstein 3D (1992) y Doom (1993), la confluencia y mixtura de estilos de los 80 confluye en una carrera hacia el realismo tridimensional y fotorrealista que rápidamente se impone como la dominante estilística del período. Esto significa que en la mayoría de los géneros se da un viraje hacia un modo de representación tridimensional y fotorrealista; es en este momento cuando se reconfiguran sensiblemente las relaciones entre videojuego y terror cinematográfico ${ }^{5}$.

Alone in the Dark, lanzado en 1992, sería leído como el iniciador de un nuevo género, el survival horror. Este género constituye el primer reconocimiento videolúdico sostenido en el tiempo del terror cinematográfico.

Volveremos más adelante sobre la presentación del cuarto momento de la periodización, que es el momento de aparición de los últimos casos del corpus.
Tanto el surgimiento como los antecedentes y la clasificación del género han sido problematizados desde los inicios del campo de los game studies (Krzywinska, 2002; Rouse, 2009; Taylor, 2009; Therrien, 2009; Pruett, 2011; Perron, 2018).

Tomo partido por la designación survival horror, en tanto es esa clasificación la que parece haber organizado (y seguir organizando) el intercambio social en torno a estos juegos, sin olvidar que distintas indagaciones sobre los recorridos del género (como las de Perron, de una gran precisión) muestran un mapa complejo de relaciones, transformaciones y préstamos. A los fines de este trabajo, alcanza con decir que el survival horror, en tanto género, supone un desvío respecto de un macrogénero como el juego de acción, que mixtura géneros preexistentes como la aventura gráfica y el puzzle (Kirkland, 2005; Egenfeldt-Nielsen, Heide Smith, Tosca, 2008).

El survival horror que emerge a comienzos de los 90 supone, entonces, una lectura austera, despojada, casi minimalista del género o macrogénero de acción, caracterizado por la abundancia y el exceso (de armas, enemigos y destrezas a desplegar): ya en Alone in the Dark (1992) la escena lúdica supone un tono reposado con un número muy limitado de adversarios a los que hay que enfrentar economizando recursos como municiones o armas blancas de poca duración (Gómez Gurpegui, 2015).

Las primeras entregas de las franquicias de Resident Evil (1996-2020) y Silent Hill (1999-2009) trabajan sobre el espectro discursivo abierto por Alone in the Dark y acaban delimitando los contornos de un género que ya cuenta tres décadas. A diferencia de los casos de 1980 analizados en el apartado anterior, el survival horror mantiene con el terror cinematográfico un vínculo explícito y duradero (Lukas, 2009).

\section{Ventanas indiscretas}

Las relaciones entre los juegos de survival horror y el terror cinematográfico se dan en muchos niveles, pero en este trabajo nos ocuparemos del jumpscare como aspecto enunciativo. Como ya se dijo, los primeros vi- 


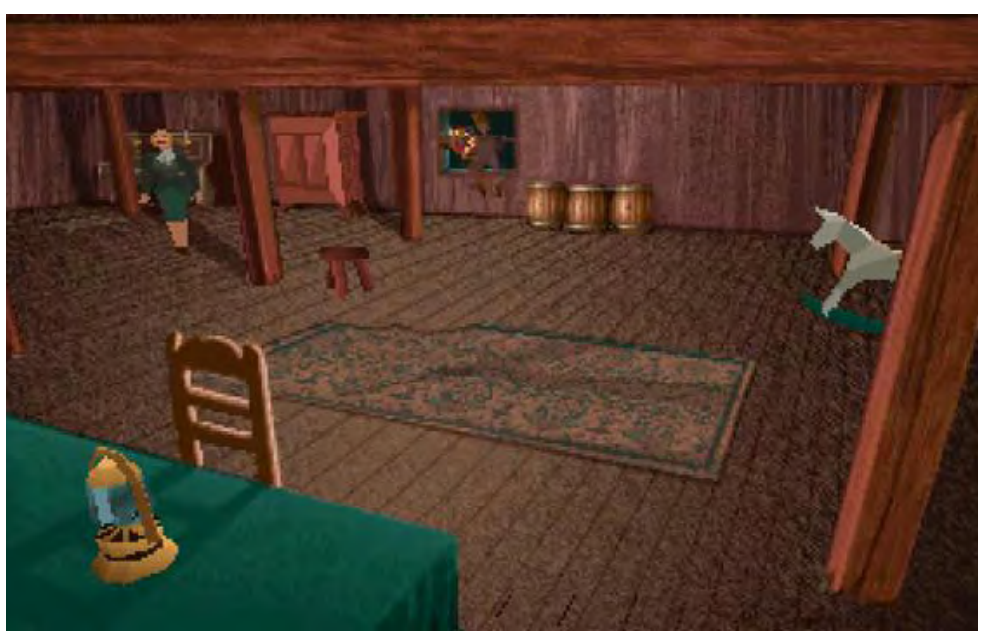

Alone in the Dark

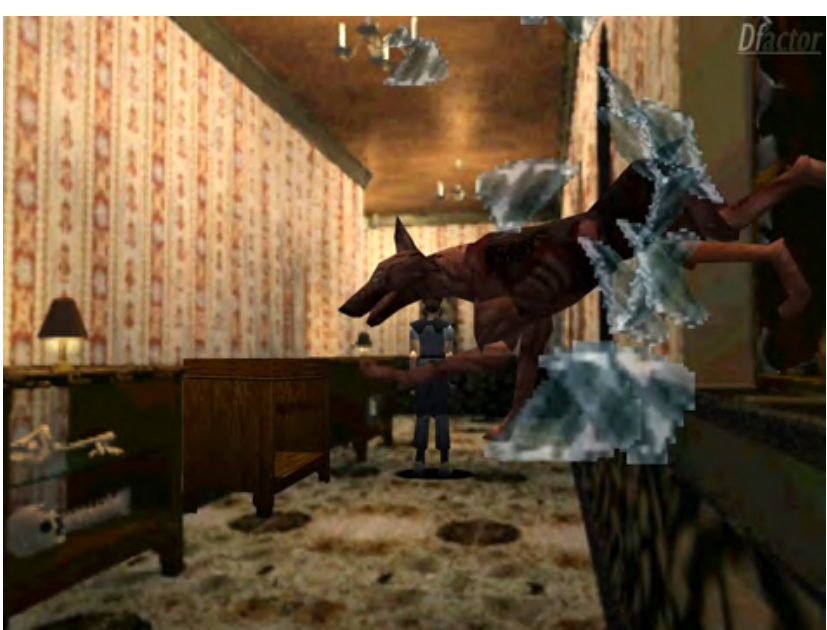

Resident Evil deojuegos que remitieron al terror no se apropiaron de rasgos del lenguaje fílmico sino que transpusieron algunas convenciones iconográficas y temáticas a formatos videolúdicos preexistentes. Esto empieza a cambiar a principios de los 90: el desarrollo de los motores gráficos en 3D abre el camino para una revolución en la representación que se da de manera más espectacular en el first-person shooter (FPS), cuya premisa central gira, justamente, en torno a la novedad del punto de vista subjetivo. Este nuevo realismo tridimensional posibilita formas de imitación del lenguaje cinematográfico que el survival horror experimentó tempranamente.

Los nuevos juegos de terror optan por un punto de vista fragmentado organizado en diferentes tipos de ángulos. A medida que el avatar se desplaza, el punto de vista cambia y muestra la acción desde distintas zonas del entorno. Esta novedad permite explotar, por un lado, la utilización del espacio en off, ya que las angulaciones tienden a dificultar la visibilidad en algunas áreas y a favorecer así la sugerencia de amenazas y trampas; por otro, la multiplicidad de puntos de vista evoca la gramática del cine, sus cambios de planos y, por lo tanto, el montaje (Krzywinska, 2002). Esto supone una gran diferencia respecto del espacio plano y del punto de vista único de los juegos mencionados en el primer apartado, pero también respecto de los first person shooter, donde el punto de vista en primera persona, único y permanente, imposibilita la réplica del lenguaje fílmico ${ }^{6}$. Los primeros juegos de las series de Alone in the Dark (1992), Resident Evil (1996) y Silent Hill (1999) entablaron un diálogo con el terror fílmico clásico partiendo de esos recursos.

Esa organización audiovisual posibilitó, a su vez, nuevas formas de generación de shock, al punto de que el recurso se volvió uno de los rasgos característicos del survival horror. Ya en Alone in the Dark aparecen diferentes formas de aprovechamiento del punto de vista para la construcción del jumpscare. En el ático, un ángulo amplio y muy acentuado muestra casi la totalidad de la habitación, dejando ver en el fondo una pequeña ventana. $\mathrm{Al}$ poco tiempo de estar en el cuarto, puede observarse a través del vidrio a una criatura; segundos después, esta rompe la ventana y entra en la habitación. La irrupción, inesperada, presentada desde ese ángulo abierto, transforma la amenaza en algo parecido a un jumpscare.

Los juegos posteriores a Alone in the Dark dedicarán una gran cantidad de insumos textuales a la elaboración del jumpscare. Uno de los momentos más recordados de

En cine, el punto de vista subjetivo es un recurso que se emplea en forma muy esporádica y los intentos de usarlo a gran escala fueron muy pocos y tuvieron un carácter experimental, como La dama del lago, de 1947, o Hardcore Henry, de 2015. En todo caso, lo «cinematográfico» de los juegos FPS no tenía que ver con la réplica del lenguaje del cine sino con la representación de un espacio tridimensional; no es este el tema del trabajo, pero puede verse operando allí un diálogo que ya no se da entre videojuego y lenguaje fílmico, sino entre videojuego y el dispositivo de la cámara. 


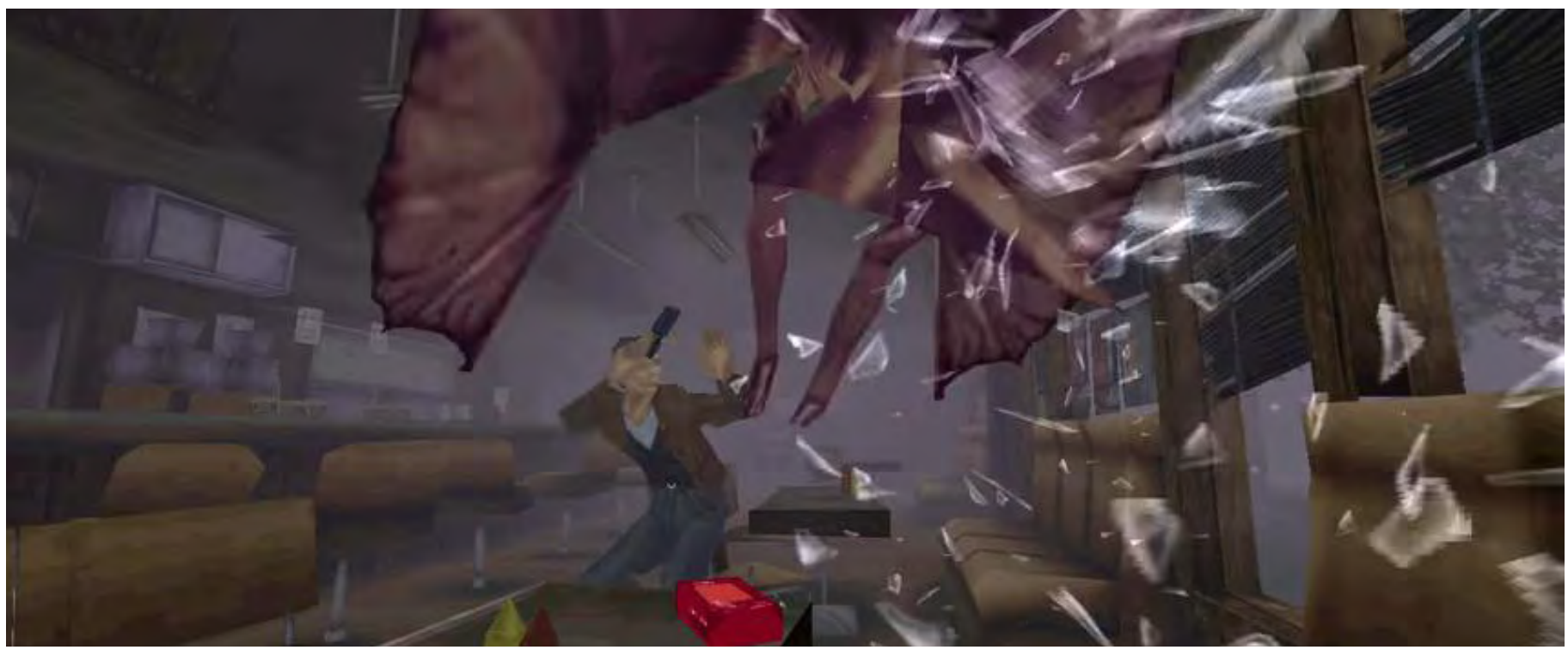

Silent Hill

Resident Evil transcurre en un pasillo con forma de L. Cuando se está llegando a la esquina, el plano levemente contrapicado, casi al ras del suelo, muestra cómo una de las ventanas estalla y a través de ella salta un perro. El jumpscare que supone el ingreso subrepticio del perro depende de la angulación: el plano muestra cómo se aleja el avatar por el pasillo y la aparición del perro sucede más cerca del punto de vista, de la «cámara». El shock se elabora a partir de una figura (el perro) que irrumpe inesperadamente en el campo visual y del ruido de los cristales de la banda sonora.

En Silent Hill, cuando el protagonista queda solo en la comisaría, escucha un sonido proveniente de una radio ubicada sobre una mesa. Cuando se dirige al sitio, un plano amplio permite observar el recinto entero. En el momento en que se prepara para agarrar la radio, en el otro extremo de la habitación, al fondo, se ven cristales de una ventana estallando hacia adentro. El avatar gira en esa dirección, pero en ese instante, cuando todo en la escena dirige la atención hacia el fondo del plano, por la ventana inmediatamente más cercana a la «cámara» irrumpe con un gran estruendo una criatura alada.
En estos breves ejemplos se nota la sofisticación de un motivo $^{7}$ : en Alone in the Dark, la aparición por la ventana se muestra en un plano general; en Resident Evil, el plano al ras del suelo le imprime potencia al ingreso inesperado del perro; en Silent Hill, la destrucción de la ventana del fondo captura la atención para que la entrada de la criatura resulte más impresionante. Este enriquecimiento del jumpscare se sostiene sobre el incremento de las posibilidades de representación que trajo la expansión de la tridimensionalidad fotorrealista y la réplica creciente del lenguaje del cine. Así, el punto de vista se transforma en el recurso que viabiliza la espectacularización de acciones que una década antes el medio apenas podía figurar. La multiplicación de puntos de vista de estos tres juegos abre un diálogo con el cine en tanto lenguaje y habilita el inicio del survival horror (Lukas, 2009), un nuevo género a partir del cual el videojuego mantiene un intercambio estable con el terror hasta el presente.

Hablar de motivo supone atender a la carga semántica de un rasgo (Panofsky, 1984; Segre, 1988). Las tres apariciones imprevistas de criaturas funcionan temáticamente, establecen una idea de mundo: confirman que se ha ingresado a un entorno signado por una amenaza sobrenatural capaz de golpear en cualquier momento. Se trata, entonces, de un motivo que podría caracterizarse como de umbral, ya que suele modelar los primeros contactos con un universo regido por leyes que no son las del mundo conocido. 
El jumpscare tiene resonancias comunicativas, es la operación retórica que moviliza, en la enunciación, el shock, la conmoción, es decir, es el recurso que más y mejor caracteriza la propuesta de contacto del género. Puede verse aquí una transformación evidente respecto de los tres primeros juegos: mientras que estos desplegaban en la escena comunicativa un sobresalto precario, los iniciadores del survival horror se apropian del jumpscare fílmico mediante la réplica de operaciones del lenguaje cinematográfico, es decir, que se trata de juegos que, en ciertos momentos, elaboran el shock de manera semejante a cómo lo haría una película.

Con el paso del tiempo, el survival horror introduce cambios en su sistema de representación y abandona el punto de vista múltiple por uno fijo, ya sea en primera o en tercera persona: esto implica grandes cambios en términos de la relación del género con el terror cinematográfico (Krzywinska, 2002) que obviamente exceden los límites de este trabajo. Por esto es que nos detenemos en la primera década del survival horror, donde la elaboración del jumpscare se elabora replicando recursos del lenguaje del cine. Continuamos, entonces, con una etapa posterior en la que el terror videolúdico ya no dialoga con el terror fílmico sino con su propio pasado mediático.

\section{Final abierto}

Retomamos ahora la periodización propuesta algunas páginas atrás. Alrededor de 2010, algunos fenómenos en expansión sugerían que se estaba entrando en una etapa radicalmente distinta. Hoy ese proceso parece más claro: después del período que comienza en los 90, y que se caracterizó por la dominancia estilística del realismo tridimensional fotorrealista, se regularizan algunos fenómenos de quiebre con la etapa anterior. Hay por lo menos cuatro procesos de ruptura:

1. el afianzamiento de un sector de producción independiente que pudo realizar experimentos expresivos por fuera de los límites de la gran industria;

2. relacionado con 1., los reenvíos del videojuego a su propio pasado mediático;
3. relacionado con 2., el surgimiento de modalidades de representación que trabajan sobre limitaciones tecnológicas de momentos previos y que, en consecuencia, toman distancia de los mandatos del realismo al uso;

4. la atenuación y desaparición de las estructuras lúdicas, que posibilitó la emergencia de funcionamientos de tipo exploratorios, inéditos en los momentos anteriores.

El cambio de período marcó la emergencia de algo nuevo: muchos juegos se apropiaron de recursos del terror pero sin suscribir plenamente al survival horror, y lo hicieron desplegando modalidades de representación que tomaron distancia del realismo y recuperaron operaciones expresivas de otros momentos previos con otras restricciones tecnológicas. Esto acabó por sistematizar reenvíos constantes hacia la producción mediática de épocas anteriores y la centralización y visibilización del píxel, la baja calidad de imagen, el espacio bidimensional, las superficies con poco detalle, etc.

Esos reenvíos confirman la entrada a un momento estilístico diferente al de los noventa: la libertad con la que una zona de la producción videolúdica se aparta de los mandatos del realismo y se apropia de los estilos del pasado hace pensar en lo que significó para el arte y la cultura el ingreso a un estadio posmoderno (Danto, 2009). Esto nos interesa, en el marco del terror y de sus subespecies, porque supone un quiebre entre videojuego y cine, o al menos un quiebre respecto de uno de los puentes que organizaban ese vínculo, que eran el realismo tridimensional y la imitación de aspectos del lenguaje fílmico. Como se verá, este quiebre gira especialmente en torno del punto de vista, que vuelve sobre modos de representación de los ochenta y abandona la réplica sensorial del lenguaje cinematográfico.

En Faith (2019), un cura viaja al campo con la misión de detener un culto que se propone invocar a un ser maligno. La representación del juego replica con cuidado la organización visual y sonora de un juego de los ochenta de dispositivos como la consola Atari $2600^{8}$. Una vez

Esta es otra característica del período: con el paso de los años, los reenvíos al pasado mediático abarcan un espectro histórico cada vez mayor y, entonces, las remisiones, en su afán mimético, se vuelven notablemente sofisticadas y diferencian momentos estilísticos y dispositivos específicos. 


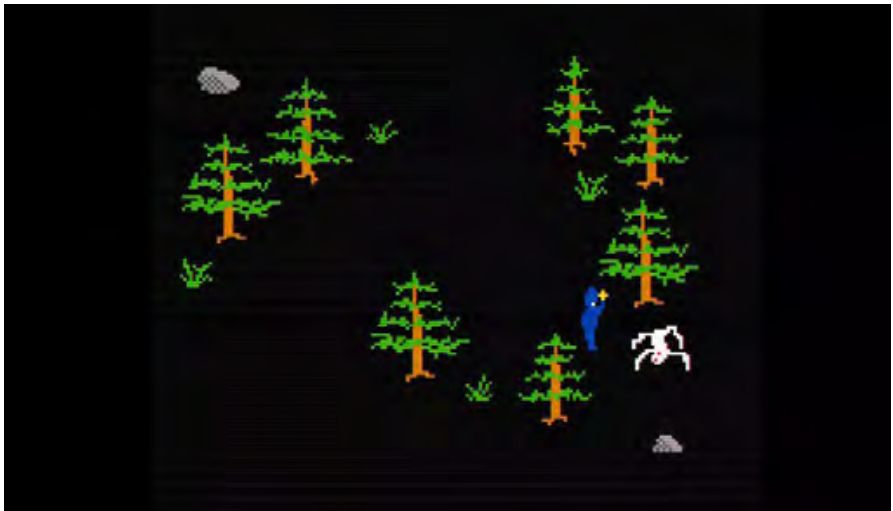

Faith

llegado al lugar, el protagonista debe recorrer la zona en busca de pistas que le permitan detener el conjuro. La semejanza con Friday the 13th resulta evidente: el punto de vista, propio de esa era, muestra la acción desde una distancia casi cenital, aunque las figuras y los objetos se ven de perfil. La réplica engloba muchos otros aspectos visuales, sonoros y lúdicos, pero detengámonos en el jumpscare: durante los recorridos por el bosque, puede aparecer sorpresivamente un monstruo que se dirige velozmente hacia el protagonista, cuya única defensa consiste en levantar en alto un crucifijo para repeler provisoriamente a la criatura.

Al no haber tridimensionalidad, el monstruo ya no puede mostrarse desde un punto de vista cercano a la «cámara» ni utilizarse la profundidad para construir el sobresalto. Por lo que el uso del sonido y del cuadro adquieren relevancia: la aparición visual del monstruo coincide con la irrupción en la banda sonora, compuesta por un montón de sonidos atonales y distorsionados que quiebran el silencio mientras la criatura resulta visible; a su vez, la aparición desde el off por algunos de los límites del encuadre es veloz y, sumado a la irrupción sonora, supone un quiebre sensorial respecto de la calma audiovisual previa. La operación muestra una nueva forma de elaborar el shock, ahora replicando los elementos constructivos de un momento mediático previo en vez de los recursos del lenguaje cinematográfico (o, al menos, de los recursos visuales del lenguaje del cine, ya que el trabajo con el sonido supone un aspecto defini- torio del jumpscare fílmico). Hanich, cuando define lo que llama shock horror, se detiene especialmente en la importancia de la utilización de una banda sonora «brusca, cortante, breve y, lo más importante, que incrementa su volumen» (136).

El reenvío a los primeros juegos del terror, previos a la emergencia del survival horror, reconfigura el despliegue del espacio y de la visualidad para el terror videolúdico más allá del tratamiento cinematográfico. Para Soderman (2016), la cuestión de la visión y la relación con los espacios in y off, si bien tiene una gran importancia en el survival horror, constituye una argamasa textual que excede al género y puede rastrearse hasta Haunted House.

Esto sucede también, aunque movilizando otros recursos, en Darkwood (2017). El juego transcurre en un bosque polaco en la década de 1980. Los habitantes son azotados por algún mal que los enloquece y transforma. Los soldados y especialistas enviados caen bajo la infección que se esparce por el sitio. El protagonista, un sobreviviente, debe abrirse paso a través de todo tipo de peligros en busca de una llave que le permita escapar por un túnel subterráneo.

El punto de vista es aéreo, top down, un modo de representación frecuente en los juegos de acción desde los 80 en adelante. Esto cancela cualquier posible diálogo con los recursos visuales del cine. El juego dispone un singular sistema de visualización: solo se observa con nitidez aquello que entra en el campo visual, con forma de cono, del avatar, el resto solo sugiere formas y

Darkwood

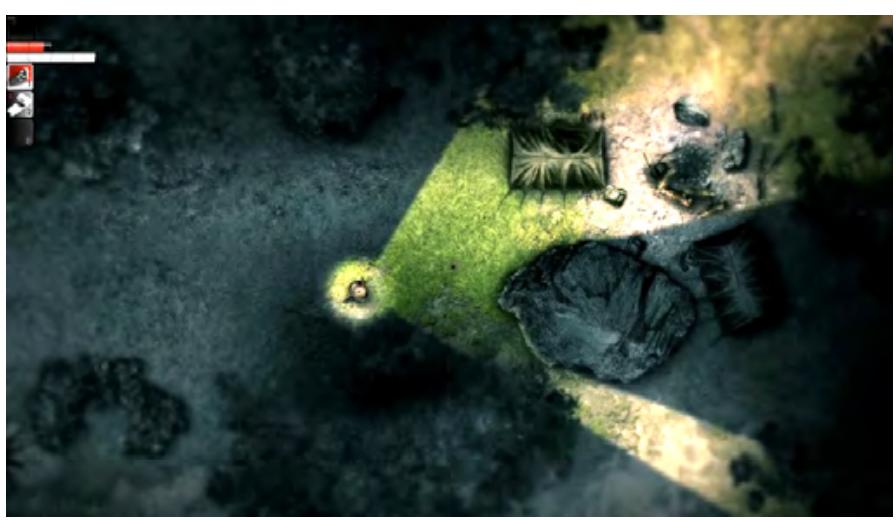


contornos neblinosos. El estado de la luz, ya sea natural o artificial, incide en el ancho y en la extensión del campo visual, por lo que los momentos nocturnos suponen una gran tensión: atrincherado en alguna casa o choza abandonada, el protagonista espera la llegada del día mientras es rodeado por monstruos que pueden irrumpir en cualquier momento por las zonas no vigiladas del lugar. El trabajo con el espacio y la visibilidad, una vez más, ya no tiene como condición de producción el terror cinematográfico (como sucedía con el survival horror) si no al ya lejano Haunted House de 1981 y los modos de representación del momento.

En el clima de tensión permanente dispuesto por el juego, el ingreso brusco de alguna criatura en el campo visual habilita un shock igual de impresionante que los de los primeros survival horror, aunque el punto de vista ya no sea el de los juegos de ese género. Ya no debería hablarse, entonces, de jumpscare, debido a que no se movilizan, como sucede en el survival horror, los recursos del cine ni del terror cinematográfico clásico. O, si mantuviéramos el término, habría que tener en cuenta que nos referimos a una operación videolúdica y no fílmica.

Para finalizar, este repliegue del videojuego sobre modos de representación previos al auge del realismo tridimensional también habilita la emergencia de estrategias textuales que evocan el terror pero sin consumarlo, que prefieren el trabajo con climas y con formas discursivas de incertidumbre. Se trata de un tipo de producción frecuente en otros lenguajes que contó con diferentes rúbricas, entre ellas, la de lo siniestro freudiano. En el caso del arte, muchas obras que retrataron lo cotidiano, lo conocido o lo familiar devenido extraño fueron clasifica- das como siniestras (Masschelein, 2011); en la literatura, Todorov dio cuenta del género fantástico como sitio de despliegue de un registro singular que oscila entre lo mágico propio de lo maravilloso y lo extraño donde la vacilación de los protagonistas se traslada al lector; en cine, la filmografía de David Lynch fue objeto recurrente de análisis concentrados en esas mismas preocupaciones estéticas (Bejarano, 2011). Ya sea que reciba el nombre de siniestro o de fantástico, existe una producción transmediática dedicada a explotar formas de incertidumbre y de ambivalencia que sugiere la posibilidad de una amenaza que nunca termina de materializarse pero que hace sentir de todas maneras su presencia ${ }^{9}$.

En el videojuego, el surgimiento de las estilísticas pixeladas del cuarto período coincide con la aparición de una nueva producción dedicada a explorar el registro fantástico. Distraint (2015) sigue a un personaje agobiado por la culpa. Price trabaja echando a inquilinos que no pueden hacer frente a sus deudas. El protagonista entra en crisis, confunde pasado y presente y sufre alucinaciones. Estamos ante un motivo típicamente fantástico, el del personaje atormentado que no se sabe si sus experiencias terribles suceden o si solo son el fruto de su psiquis destrozada (Todorov, 2011). El juego explota esa premisa desplegando escenas y eventos cuya ambigüedad nunca revela plenamente su estatuto de verdad o de desvarío.

En uno de los momentos más celebrados del juego, Price encuentra en una pared una nota ensangrentada

En relación con el videojuego, me ocupé de analizar modos de funcionamiento de lo siniestro tanto en producción como en reconocimiento (Maté, 2019b; Maté, 2019a).

\section{Distraint}

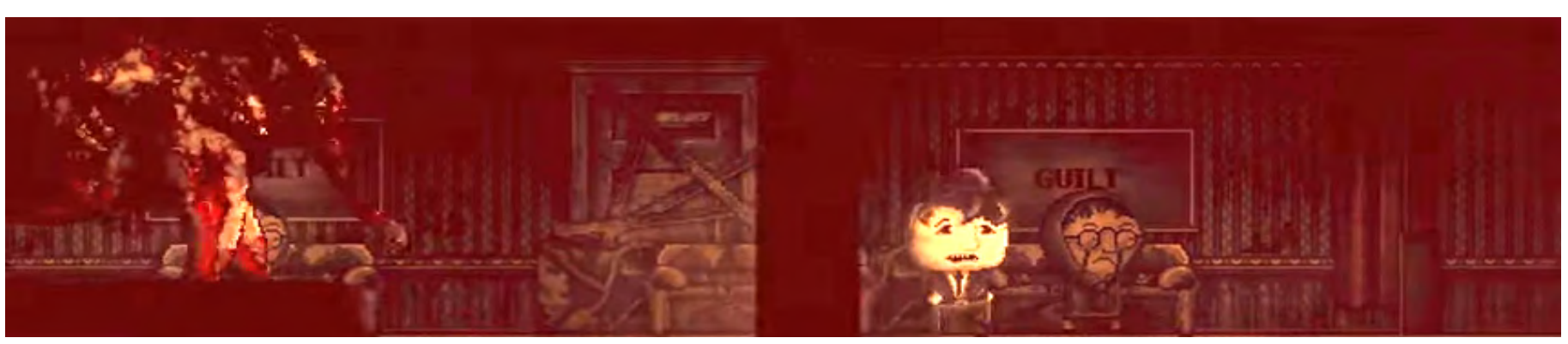


que dice: «hay un elefante en la habitación». El personaje la lee y comenta para sí mismo que conoce el refrán. En el desarrollo narrativo, la frase funciona como metáfora que cifra la imposibilidad del protagonista de lidiar con sus problemas. Sin embargo, una vez leída la nota, un sonido anuncia que algo está por suceder: por el margen izquierdo del cuadro se ve aparecer un elefante en estado de putrefacción que se aproxima velozmente hacia el avatar ubicado en la zona derecha de la imagen. La pesquisa reposada del entorno se transforma de golpe en una carrera frenética para escapar del elefante, metáfora ahora literalizada que deviene monstruo perseguidor. Después de la aparición del elefante y de la huida, Price despierta en su cama y se prepara para un nuevo día: la persecución tal vez haya sido una pesadilla, pero segundos antes el peligro resultaba tangible y su existencia no podía explicarse según las reglas de lo onírico. Vemos operando aquí, según Todorov, un recurso típicamente fantástico como es la literalización textual de figuras retóricas.

La aparición del elefante en Distraint muestra cómo el shock puede gestionarse con una representación en dos dimensiones, semejante a la del género de plataformas, que históricamente estuvo alejado de las tematizaciones ligadas al terror. Al igual que en los dos casos anteriores, se aprovecha el uso del espacio off, aunque Distraint exhibe una diferencia notoria ya que la premisa de partida, que incluye a un personaje desequilibrado que confunde presente con pasado, lo real con alucinaciones, desplaza el discurso de los dominios del terror de los casos previos y lo lleva hacia el terreno de lo siniestro. Este deslizamiento señala la pertenencia a un registro que ya no es el del terror tradicional sino el de lo fantástico todoroviano, que pone en duda el estatuto de los hechos y trabaja con la vacilación como procedimiento organizador. Como explica Todorov, es condición de posibilidad de lo fantástico que la incertidumbre que tortura a los personajes se traslade a la experiencia de lectura, es decir, que la duda respecto del carácter de los hechos desborde el relato y alcance al discurso en su totalidad, que la vacilación de los protagonistas funcione también enunciativamente.

\section{Conclusiones}

El análisis de las formas de producción de shock en juegos que evocan el género de terror, o que se lo apropian bajo la configuración del survival horror, permite trazar un breve estado de situación de las relaciones entre cine y videojuego. Breve, necesariamente, pero también localizado, circunscripto, ya que las formas de articulación entre la producción de uno y otro lenguaje son muchas y recortan un campo de fenómenos mucho más grande.

La cuestión del terror y de la búsqueda del shock como efecto enunciativo muestra tres estadios distintos: en el primero, el videojuego trata de imitar el jumpscare del terror cinematográfico; en el segundo, el survival horror replica el jumpscare mediante la apropiación de aspectos que hacen a la visualidad cinematográfica (especialmente el uso de la profundidad, la multiplicidad de planos y el montaje); en el tercero, el videojuego experimenta con formas de producción de shock que ya no tienen como insumo el lenguaje del cine sino géneros y estilos videolúdicos de momentos históricos previos.

Lo relevante para los fines de este trabajo, en todo caso, son las transformaciones a gran escala que muestra la circulación del sentido en la producción del videojuego: en estos movimientos, el cine aparece primero como horizonte expresivo distante y como organizador sensorial y de género después; un antes y un después del terror cinematográfico.

El tercer estadio coincide con el cuarto momento de nuestra periodización y, por lo tanto, supone el ingreso a una etapa distinta en las que se dibujan fenómenos de una gran complejidad: por un lado, el crecimiento y la diversificación de los reenvíos del videojuego a su propio pasado mediático (algo que hubiera sido impensado hace apenas una década y media); por otro, la aparición de juegos como Distraint, donde el trabajo con la incertidumbre y la ambivalencia alejan al videojuego de la producción mainstream y señalan la emergencia de una oferta discursiva semejante a la que en otros lenguajes fue clasificada como moderna. 
Se trata de un vaivén recurrente en la cultura: el quiebre sistemático respecto de un sistema de normas previas confirma el carácter moderno de la nueva producción. No hubo nada parecido a una posible modernidad en el videojuego hasta el ingreso, hace apenas unos diez años, a esta nueva etapa. El abandono de la réplica del lenguaje cinematográfico y el repliegue sobre el repertorio expresivo del propio medio confirman la singularidad del momento presente, del que todavía sabemos demasiado poco.

El survival horror condensó, entonces, una búsqueda estilística que definió el lugar mediático del videojuego desde los noventa hasta el presente. La imitación de los recursos constructivos del cine, de la profundidad, del fotorrealismo, constituyó la operación privilegiada mediante la cual el videojuego trazó un horizonte estilístico que llega hasta nuestros días: de esta forma, el cine devino la condición de posibilidad de un realismo videolúdico que tuvo en el survival horror uno de sus principales pilares. Podría afirmarse, así, que la incipiente modernidad en la que se encuentra el medio, y la autoconciencia respecto de su propia historia estilística, implica, como gesto decisivo, el abandono del lenguaje cinematográfico y la recuperación de los estilos de un pasado que, hasta hace una década, habían sido obturados por la hegemonía del fotorrealismo tridimensional.

\section{Bibliografía}

Bejarano, Carolina. «La visualidad siniestra». Revista Figuraciones, 8, 2011.

Bishop, Bryan. «'Why won't you die?!' The art of the jump scare.». The Verge, 31 de octubre de 2012, https://www.theverge.com/2012/10/31/3574592/ art-of-the-jump-scare-horror-movies

Carrol, Noël. Filosofía del terror o paradojas del corazón. Madrid: Antonio Machado, 2005.

Danto, Arthur. Después del fin del arte. El arte contemporáneo y el fin de la historia. Buenos Aires: Paidós, 2009

Draven, Danny. Genre Filmmaking: A Visual Guide to Shots and Style for Genre Films. London: Routledge, 2013.
Egenfeldt-Nielsen, Simon, Jonas Heide Smith y Susana Tosca. Understanding Video Games: The Essential Introduction. London: Francis \& Taylor, 2008.

Fernández-Vara, Clara. The Tribulation of adventure games: Integrating story into simulation through performance. Atlanta: Georgia Institute of Technology, 2009 (Doctoral Dissertation).

Freud, Sigmund. «Lo ominoso». Obras completas de Sigmund Freud. Volumen XVII (1917-1919). Buenos Aires: Amorrortu, 1992.

Gómez Gurpegui, Carlos. La construcción del terror en los videojuegos: Alien: Isolation. Madrid: Universidad Rey Juan Carlos, 2015 (Tesis de Maestría).

Hanich, Julian. Cinematic Emotion in Horror Films and Thrillers. The Aesthetic Paradox of Pleasurable Fear.London: Routledge, 2010.

Kent, Steven. The Ultimate History of Video Games: From Pong to Pokemon. The Story behind the Craze That Touched Our Lives and Changed the World. Rocklin: Prima Communications, 2001.

Kirkland, Ewan. «Restless Dreams in Silent Hill: Approaches to Videogame Analysis». Journal of Media Practice, 6, 2005, pp. 167-178.

Krzywinska, Tania. «Hands on Horron». ScreenPlay: Cinema/Videogames/Interfaces. Eds. Geoff King y Tania Krzywinska. London: Wallflower Press, 2002, pp. 206-223.

Lukas, Scott. «Horror Video Game Remakes and the Question of Medium: Remaking Doom, Silent Hill, and Resident Evil». Fear, Cultural Anxiety and Transformation: Horror, Science Fiction and Fantasy Films Remade. Eds. John Marmysz and y Scott Lukas. Maryland: Lexington Books, 2009, pp. 221-242.

Masschelein, Anneleen. The Unconcept: The Freudian Uncanny in Late-Twentieth-Century Theory. New York: SUNY Press, 2011

Maté, Diego. «Modalidades de lectura de lo siniestro desde el glitch en el videojuego: viejos temores, nuevos placeres». Revista Chilena de Semiótica, 11, 2019(a) pp. 166-182, https://revistachilenasemiotica.cl/_ files/200000227-b4cd1b4cd5/RCHS-11-FINAL. pdf 
- «Al final del pasillo. Modalidades de lo siniestro en el videojuego». Boletín de Arte, 19, 2019 (b), pp. 1-17, https://doi.org/10.24215/23142502e015

- «Notas para una periodización del videojuego». Maté, D. (coord.) Cuadernos del Instituto. Investigación y Experimentación en Arte y Crítica, 6, 2020 (En prensa). Metz, Christian. «El estudio semiológico del lenguaje cinematográfico». Lenguajes, 1, 2. Buenos Aires: Nueva Visión, 1974, pp. 37-51.

Muir, John Kenneth. Horror Films FAQ: All That's Left to Know about Slashers Vampires Zombies Aliens and More. Maryland: Rowman \& Littlefield, 2013.

Panofsky, Erwin. Estudios sobre iconología. Madrid: Alianza Universitaria, 1984.

Perron, Bernard. «Introduction: Gaming after Dark». Horror Video Games: Essays on the Fusion of Fear and Play. Ed. Bernard Perron. Jefferson, NC: McFarland \& Company, 2009, pp. 3-14.

- The World of Scary Video Games. A Study in Videoludic Horror. New York: Bloomsbury, 2018.

Picard, M. «Haunting Backgrounds: Transnationality and Intermediality in Japanese Survival Horror Video Games». Horror Video Games: Essays on the Fusion of Fear and Play. Ed. Bernard Perron. Jefferson, NC: McFarland \& Company, 2009, pp. 95-120.

Pinedo, Isabel. «Postmodern Elements of the Contemporary Horror Film». The Horror Film. Ed. Stephen Prince. New Jersey: Rutgers University Press, 2004, pp. 85-117.

Prince, Stephen. «Introduction: The Dark Genre and Its Paradoxes». The Horror Film. Ed. Stephen Prince. New Jersey: Rutgers University Press, 2004, pp. 1-14. Pruett, Chris. «The Prehistory of Survival Horror». Chris's Survival Horror Quest, 12 de junio 2011, http:/ / horror.dreamdawn.com/?p=74151
Riviello, Alex. «A Brief History of the Horror Movie Jump Scare». Slash Film, 16 de agosto de 2017, https:/ /www.slashfilm.com/a-brief-history-of-thehorror-movie-jump-scare/

Rouse, Richard. «Match Made in Hell: The Inevitable Success of the Horror Genre in Video Games». Horror Video Games: Essays on the Fusion of Fear and Play. Ed. Bernard Perron. Jefferson, NC: McFarland \& Company, 2009, pp. 15-25.

Ryan, Marie-Laure. Narrative as virtual reality 2. Revisiting immersion and interactivity in literature and electronic media. Baltimore: John Hopkins University Press, 2015.

Segre, Cesare. Principios de análisis del texto literario. Barcelona: Crítica, 1988.

Soderman, Braxton. «'Don’t Look... Or It Takes you’: The Games of Horror Vacuì. Journal of Visual Culture, 14(3), 2016, pp. 311-316.

Steimberg, Oscar. Semióticas. Las semióticas de los géneros, de los estilos, de la transposición. Buenos Aires: Eterna Cadencia, 2013.

Taylor, Laurie. «Gothic Bloodlines in Survival Horror Gaming». Horror Video Games: Essays on the Fusion of Fear and Play. Ed. Bernard Perron. Jefferson, NC: McFarland \& Company, 2009, pp. 46-61.

Therrien, Carl. «Games of Fear: A multi-Faceted Historical Account of the Horror Genre in Video Games». Horror Video Games: Essays on the Fusion of Fear and Play. Ed. Bernard Perron. Jefferson, NC: McFarland \& Company, 2009, pp. 26-45.

Todorov, Tzvetan. Introducción a la literatura fantástica. Buenos Aires: Paidos. 2011.

Verón, Eliseo. La semiosis social. Barcelona: Gedisa, 1998.

- «Cuando leer es hacer: la enunciación en la prensa gráfica». Fragmentos de un tejido. Barcelona: Gedisa, 2005, pp. 171-191. 